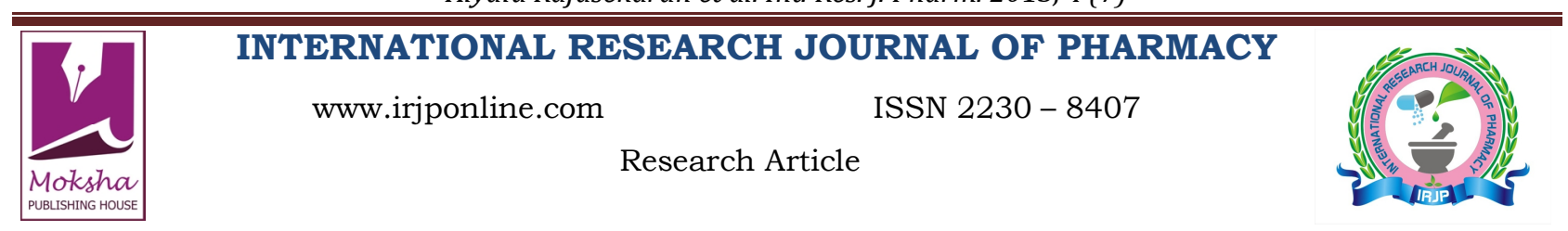

\title{
SIMULTANEOUS ESTIMATION OF LUTEOLIN AND APIGENIN IN METHANOLIC LEAF EXTRACT OF CARDIOSPERMUM HALICACABUM BY HPLC
}

\author{
Aiyalu Rajasekaran ${ }^{1 *}$, Vivekanandan Kalaiselvan ${ }^{2}$, Nagulsamy Sarathikumar ${ }^{1}$, Muthusamy Kalaivani ${ }^{2}$ \\ ${ }^{1} \mathrm{KMCH}$ College of Pharmacy, Coimbatore, Tamil Nadu, India \\ ${ }^{2}$ Indian Pharmacopoeia Commission, New Delhi, India \\ *Corresponding Author Email: rsekaran2001in@yahoo.co.in
}

Article Received on: 20/03/13 Revised on: 09/04/13 Approved for publication: 13/05/13

DOI: 10.7897/2230-8407.04724

IRJP is an official publication of Moksha Publishing House. Website: www.mokshaph.com

(C) All rights reserved.

\section{ABSTRACT}

Cardiospermum halicacabum (Sapindaceae) widely spread in Asia, tropical and sub-tropical Africa is commonly consumed as leafy vegetable for the treatment of rheumatoid arthritis in India. The present study was aimed to develop and validate an RP-HPLC separation for the simultaneous estimation of luteolin and apigenin in the leaves of Cardiospermum halicacabum. HPLC separation was accomplished on an oyster ODS 3 column $(5 \mu \mathrm{m}, 200 \mathrm{~mm} \times 4.6$ $\mathrm{mm}$, i.d.) with gradient elution of potassium dihydrogen phosphate buffer $(20 \mathrm{mM}, \mathrm{pH} 3.5$ adjusted with ortho phosphoric acid, $\mathrm{v} / \mathrm{v})$ (A) and acetonitrile (B). The elution program as follows; $0-10 \min 15-60 \% \mathrm{~B}, 10-15 \mathrm{~min} 60-75 \% \mathrm{~B}, 15-20 \mathrm{~min} 75-100 \% \mathrm{~B}, 20-25 \mathrm{~min}$ B hold at $100 \%$. The method was validated as per ICH guidelines for system suitability, linearity, specificity, precision, accuracy, LOD and LOQ. The method was linear in the range of 1-70 $\mu \mathrm{g} / \mathrm{ml}$. The relative standard deviation of the method was less than $2 \%$ for intra-day and inter-day precision assay and the average recoveries were between 98 and $102 \%$. LOD, LOQ of luteolin and apigenin was found to be $0.03,0.91$ and $0.041,0.13 \mu \mathrm{g} / \mathrm{ml}$ respectively. The proposed method was found to be linear, specific, accurate, precise and robust.

Keywords: Cardiospermum halicacabum; apigenin; luteolin; RP-HPLC

\section{INTRODUCTION}

Cardiospermum halicacabum (C.H) commonly called as balloon vine is found in the soapwort family (Sapindaceae) and represents more than 30 recognized species throughout the world. Cardiospermum halicacabum is widely spread in tropical and sub-tropical Africa, Asia and in India is most commonly used for the treatment of rheumatoid arthritis ${ }^{1}$. Besides antioxidant activity $^{2}$ the plant was reported for analgesic and vasodepressant activities ${ }^{3}$, antipyretic activity against yeast-induced pyrexia in rats $^{4}$, antimalarial activity ${ }^{5}$, diuretic activity ${ }^{6}$, anti-diarrhoeal activity $^{7}$, anti-diabetic activity $^{8}$ and anti-ulcer activity ${ }^{9}$. Flavonoids viz. apigenin and luteolin was reported to be present in the leaves of Cardiospermum halicacabum ${ }^{10-12}$. A UV and polarographic method $^{13}$, RP-HPLC ${ }^{14}$ and a HPTLC ${ }^{15}$ method was reported for the estimation of luteolin in plant extracts. A rapid RPHPTLC densitometry method for simultaneous determination of luteolin, apigenin and other major flavonoids in important medicinal plants was reported by Bhandari et $a l^{16}$. Two RPHPLC methods were reported for the estimation of luteolin and apigenin in plant extract of Cardiospermum halicacabum $^{17,18} \mathrm{Li}$ et al ${ }^{19}$ reported a simultaneous estimation of luteolin and apigenin in dog plasma by RP-HPLC method. There is no report available about the determination of luteolin and apigenin in Cardiospermum halicacabum. Hence the present study was undertaken to develop a validated RPHPLC method for the quantification of apigenin and luteolin in Cardiospermum halicacabum.

\section{MATERIALS AND METHODS Plant material}

The plant Cardiospermum halicacabum was collected from the hills of Palakkad district of Kerala, India and it was authenticated by Dr. G.V.S. Murthy, Scientist "E" Botanical survey of India, Coimbatore, Tamil Nadu, India. The voucher specimen for future reference was deposited in our pharmacognosy laboratory.

\section{Chemicals, solvents and standards}

Analytical grade methanol (Merck, Mumbai, India) was used for extraction, while HPLC-grade acetonitrile, methanol, orthophosphoric acid and analytical grade potassium dihydrogen orthophosphoric acid (Merck, Mumbai, India) were used in HPLC analysis. Standards of apigenin and luteolin were obtained from LGC prochem, Bengaluru, India.

\section{Chromatographic instrumentation and conditions}

The analysis was carried out with a Hewlett-packard 1100 series HPLC system (Agilent Technologies, Palo Alto, CA, USA) comprising a quaternary pump (HP $1311 \mathrm{~A}$ ), a vacuum degasser (Agilent $1322 \mathrm{~A}$ ), a variable wavelength detector (HP 1314A) and a $20 \mu \mathrm{l}$ sample injector (Rheodyne 7725), column thermostat (HP 1316). The separation was performed on Oyster ODS 3 column $(5 \mu \mathrm{m}, 200 \mathrm{~mm} \mathrm{X} 4.6 \mathrm{~mm}$, i.d, Merck). The detection wavelength was set at $348 \mathrm{~nm}$. The mobile phase consisted of solvent A (20 mM potassium dihydrogen phosphate, $\mathrm{pH} 3.5$ adjusted with orthophosphoric acid $\mathrm{v} / \mathrm{v}$ ), solvent $\mathrm{B}$ acetonitrile with the elution profile as follows: $0-10 \mathrm{~min}, 15-60 \% \mathrm{~B}$; $10-15 \mathrm{~min}, 60-75 \% \mathrm{~B} ; 15-20$ $\min , 75 \% \mathrm{~B} ; 20-25 \mathrm{~min}, 75-100 \% \mathrm{~B}$ with the flow rate of 1 $\mathrm{ml} / \mathrm{min}$. The column thermostat was maintained at $30 \pm 1{ }^{\circ} \mathrm{C}$.

\section{Preparation of plant extract}

Cardiospermum halicacabum leaf was finely powdered; $10 \mathrm{~g}$ of the powder content was transferred into a $250 \mathrm{ml}$ beaker, macerated with $3 \times 50 \mathrm{ml}$ of methanol for $24 \mathrm{~h}$, filtered through Whatman filter No 1. The extracts were concentrated in vacuum rotary evaporator (Buchi, German).

\section{Preparation of Standard stock solutions}

Ten mg each of apigenin and luteolin weighed accurately and transferred separately into a $10 \mathrm{ml}$ volumetric flask, dissolved in $5 \mathrm{ml}$ of methanol, sonicated for $5 \mathrm{~min}$ and the final volumes made up with acetonitrile to produce $1 \mathrm{mg} / \mathrm{ml}$ stock solution. 


\section{Preparation of sample solution}

Ten mg of leaf extract was weighed accurately, transferred into a $10 \mathrm{ml}$ volumetric flask and dissolved in $5 \mathrm{ml}$ of methanol followed by sonication for $5 \mathrm{~min}$ and made up to volume with acetonitrile. $0.2 \mathrm{ml}$ of the solutions was further diluted to $10 \mathrm{ml}$ with acetonitrile, filtered through $0.45 \mu \mathrm{m}$ nylon filter paper prior to use.

\section{Validation of the HPLC method}

The method was validated as per ICH guidelines ${ }^{20}$ for system suitability, linearity, accuracy, precision, robustness, sensitivity, LOD and LOQ by the following procedures (Figure 1 to 4 ).

\section{System suitability}

System suitability of method was performed by calculating the chromatographic parameters namely, column efficiency, resolution, peak asymmetry factor and HETP on the repetitive of injection of standard solution.

\section{Linearity (Calibration curve)}

Linearity was performed for each apigenin and luteolin standards with five different concentrations between the ranges of 1-70 $\mu \mathrm{g} / \mathrm{ml}$ were analysed in triplicate for each concentration. Calibration curves were constructed by plotting peak areas against analyte concentrations. The linearity was assessed by calculating the slope, y-intercept and coefficient of determination $\left(\mathrm{r}^{2}\right)$ using Microsoft Excel 2007 program

\section{Precision}

The precision of the method was examined by performing the intra-day and inter-day assays of six replicate injections of the mixture of standard solution at three concentration levels $(1,30$ and $70 \mu \mathrm{g} / \mathrm{ml})$. The intraday assay precision test was performed at intervals of $4 \mathrm{~h}$ in 1 day, while the interday assay precision test was performed over 3 days.

\section{LOD and LOQ}

LOD and LOQ of both the analytes were determined by $k$ $\mathrm{SD} / b$ where $k$ is a constant (3.3 for LOD and 10 for LOQ),
$\mathrm{SD}$ is the standard deviation of the analytical signal, and $b$ is the slope of the concentration/response graph.

\section{Accuracy}

The accuracy of the method was determined by calculating the recoveries of apigenin and luteolin by the method of standard addition. Known amount of the standards (80, 100 and $120 \%$ ) were added to the pre-analyzed sample solutions and the amounts of these standards were estimated by measuring the peak areas and by fitting these values to the straight-line equation of calibration curves.

\section{Robustness}

The robustness of the proposed method was evaluated by changing the different $\mathrm{C} 18$ column brand, $\mathrm{pH}$ and extraction time.

\section{Specificity}

Specificity is the ability of an analytical method to differentiate and quantify the analyte in presence of other components in the sample. Peak purity of the method was evaluated by calculating the difference between peak angle $\left(\theta_{\mathrm{p}}\right)$ and peak threshold angle $\left(\theta_{\mathrm{th}}\right)$. Peak purity was assessed using millennium 32 software for waters HPLC/PDA; system based on the degree of similarity of UV spectra across the peak in the range of $190-800 \mathrm{~nm}$. The separation was performed on a Hypersil C18 column (particle size $5 \mu \mathrm{m} ; 250$ $\mathrm{X} 4.6 \mathrm{~mm}$ id).

Table 1: System suitability parameters of luteolin and apigenin

\begin{tabular}{|c|c|c|}
\hline Parameters & Luteolin $(\mathbf{1} \boldsymbol{\mu g} / \mathbf{m l})$ & Apigenin $(\mathbf{1} \boldsymbol{\mu} \mathbf{g} / \mathbf{m l})$ \\
\hline $\begin{array}{c}\text { Number of } \\
\text { theoretical plates }\end{array}$ & 21211 & 33492 \\
\hline Asymmetry factor & 0.69 & 0.81 \\
\hline Resolution & 5.42 & 3.11 \\
\hline HETP & 0.94 & 0.59 \\
\hline
\end{tabular}

Table 2: Peak purity profile of luteolin and apigenin

\begin{tabular}{|c|c|c|}
\hline Components & Peak angle & Threshold \\
\hline Luteolin $(5 \mu \mathrm{g} / \mathrm{ml})$ & 0.669 & 3.773 \\
\hline Apigenin $(5 \mu \mathrm{g} / \mathrm{ml})$ & 0.321 & 4.601 \\
\hline
\end{tabular}

Table 3: Linear regression data for the calibration curves $(n=3)$

\begin{tabular}{|c|c|c|}
\hline Parameter & luteolin & apigenin \\
\hline Retention time $(\mathrm{min})$ & $7.024 \pm 0.118$ & $7.614 \pm 0.107$ \\
\hline Detection wavelength & $348 \mathrm{~nm}$ & $348 \mathrm{~nm}$ \\
\hline LOD $\mu \mathrm{g} / \mathrm{ml}$ & 0.03 & 0.04 \\
\hline LOQ $\mu \mathrm{g} / \mathrm{ml}$ & 0.91 & 0.13 \\
\hline Linearity range $\mu \mathrm{g} / \mathrm{ml}$ & $1-70$ & $1-70$ \\
\hline Correlation coefficient (area) & 0.9995 & 0.9998 \\
\hline Regression equation (area) & $\mathrm{y}=151.99 \mathrm{x}+26.60$ & $\mathrm{y}=124.16 \mathrm{x}+37.51$ \\
\hline
\end{tabular}

Table 4: Intra and interday precision of the developed method $(n=6)$

\begin{tabular}{|c|c|c|c|c|c|c|c|c|}
\hline \multirow[b]{3}{*}{ components } & \multicolumn{4}{|c|}{ Intraday } & \multicolumn{4}{|c|}{ Interday } \\
\hline & \multicolumn{2}{|c|}{ Retention time } & \multicolumn{2}{|c|}{ Peak area } & \multicolumn{2}{|c|}{ Retention time } & \multicolumn{2}{|c|}{ Peak area } \\
\hline & Mean & $\%$ RSD & Mean & $\%$ RSD & Mean & $\%$ RSD & Mean & \%RSD \\
\hline \multicolumn{9}{|c|}{ luteolin } \\
\hline $1 \mu \mathrm{g} / \mathrm{ml}$ & 7.09 & 0.13 & 302 & 0.75 & 7.06 & 0.06 & 297 & 0.95 \\
\hline $30 \mu \mathrm{g} / \mathrm{ml}$ & 7.05 & 0.24 & 4492 & 1.18 & 7.01 & 0.26 & 4469 & 1.36 \\
\hline $70 \mu \mathrm{g} / \mathrm{ml}$ & 7.02 & 0.27 & 10748 & 0.93 & 6.96 & 0.36 & 10639 & 1.27 \\
\hline \multicolumn{9}{|c|}{ apigenin } \\
\hline $1 \mu \mathrm{g} / \mathrm{ml}$ & 7.59 & 0.18 & 217 & 0.58 & 7.57 & 0.09 & 209 & 0.93 \\
\hline $30 \mu \mathrm{g} / \mathrm{ml}$ & 7.62 & 0.17 & 3754 & 1.18 & 7.59 & 0.39 & 3684 & 1.42 \\
\hline $70 \mu \mathrm{g} / \mathrm{ml}$ & 7.64 & 0.35 & 8649 & 1.32 & 7.62 & 0.27 & 8598 & 1.63 \\
\hline
\end{tabular}


Aiyalu Rajasekaran et al. Int. Res. J. Pharm. 2013, 4 (7)

Table 5: Recovery study of luteolin and apigenin from the extract of Cardiospermum halicacabum (n=3)

\begin{tabular}{|c|c|c|c|c|c|}
\hline Components & Quantity added \% & Total quantity present, $\mu \mathrm{g} / \mathrm{ml}$ & Amount quantity found, $\mu \mathrm{g} / \mathrm{ml}$ & Recovery, \% & \%RSD \\
\hline \multirow{4}{*}{ luteolin } & 0 & 0.130 & 0.128 & 98.46 & 0.84 \\
\hline & 80 & 0.234 & 0.231 & 98.71 & 0.69 \\
\hline & 100 & 0.260 & 0.258 & 99.23 & 1.26 \\
\hline & 120 & 0.286 & 0.271 & 98.95 & 1.51 \\
\hline \multirow{4}{*}{ apigenin } & 0 & 0.436 & 0.431 & 98.85 & 0.93 \\
\hline & 80 & 0.784 & 0.782 & 99.74 & 1.28 \\
\hline & 100 & 0.872 & 0.863 & 98.96 & 1.86 \\
\hline & 120 & 0.959 & 0.941 & 98.12 & 1.15 \\
\hline
\end{tabular}

Table 6: Robustness of the method $(n=6)$

\begin{tabular}{|c|c|c|c|}
\hline \multicolumn{2}{|c|}{ Parameters changed } & \multicolumn{2}{c|}{ Recovery, \% \pm SD } \\
\cline { 3 - 4 } \multicolumn{2}{|c|}{} & luteolin & apigenin \\
\hline \multirow{3}{*}{ Extraction time } & $20 \mathrm{~h}$ & $98.36 \pm 1.34$ & $98.92 \pm 0.49$ \\
\cline { 2 - 4 } & $24 \mathrm{~h}$ & $99.52 \pm 0.98$ & $101.56 \pm 0.72$ \\
\cline { 2 - 4 } & $48 \mathrm{~h}$ & $101.83 \pm 1.19$ & $99.82 \pm 1.28$ \\
\hline \multirow{3}{*}{$\mathrm{pH}$} & 3.0 & $98.78 \pm 0.97$ & $99.71 \pm 1.32$ \\
\cline { 2 - 4 } & 3.5 & $99.39 \pm 0.70$ & $100.39 \pm 0.97$ \\
\cline { 2 - 4 } & 4.0 & $98.38 \pm 1.25$ & $98.58 \pm 1.62$ \\
\hline Column brand & Zobrax & $99.29 \pm 0.73$ & $99.37 \pm 0.83$ \\
\cline { 2 - 4 } & Oyster & $98.93 \pm 0.83$ & $98.49 \pm 0.39$ \\
\cline { 2 - 4 } & Hypersil & $101.53 \pm 1.14$ & $98.24 \pm 1.85$ \\
\hline
\end{tabular}

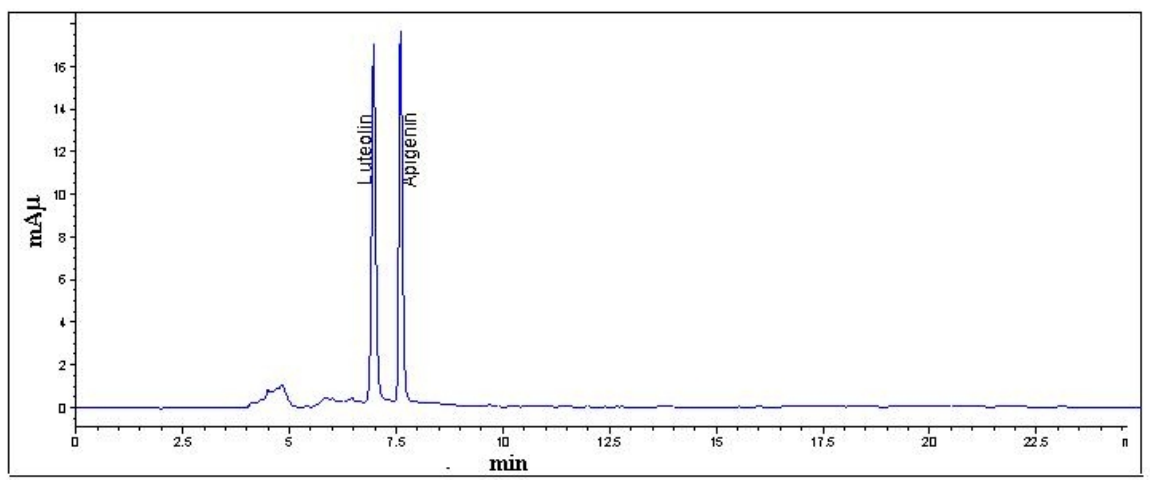

Figure 1. Chromatogram of luteolin and apigenin standards

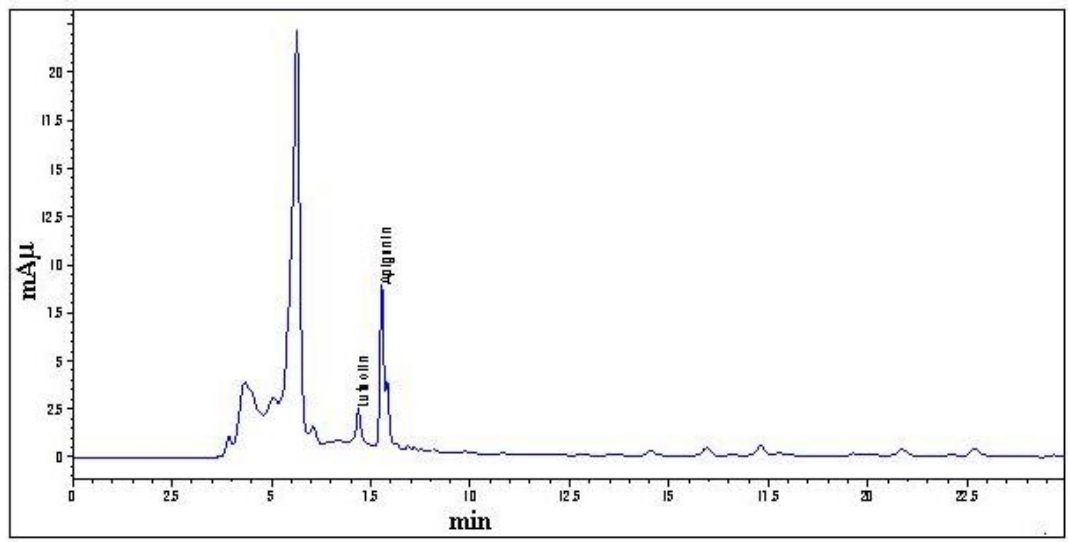

Fig.2. Chromatogram of Cardiospermum halicacabum leaf extract 


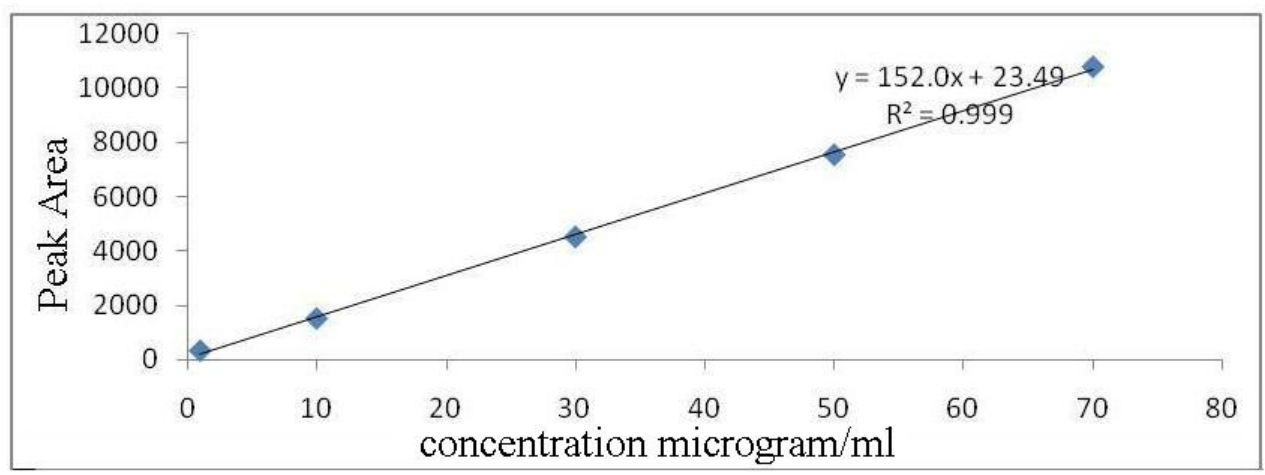

Fig.3 Linearity of luteolin standard

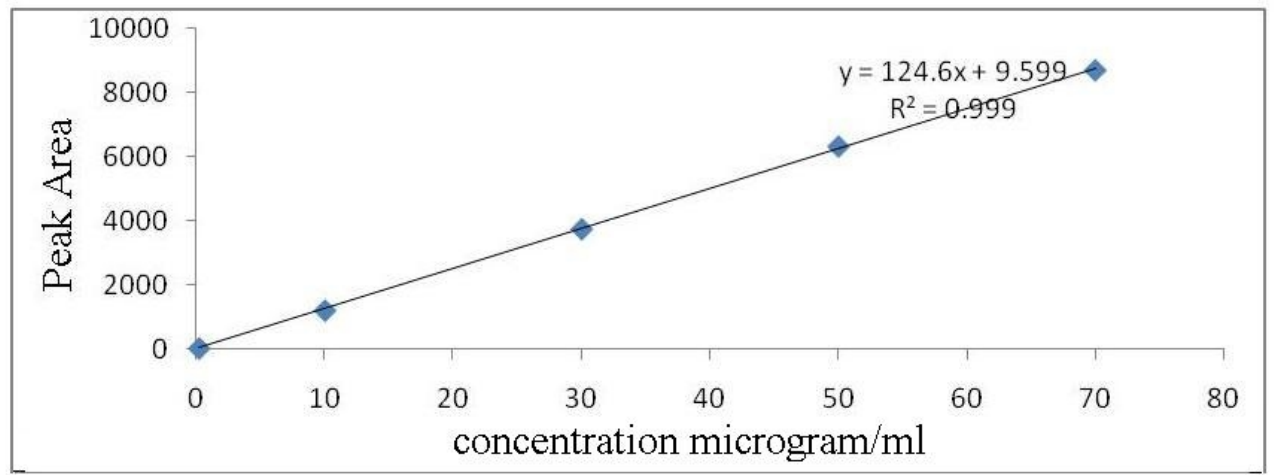

Fig.4. Linearity of apigenin standard

\section{RESULTS AND DISCUSSION}

\section{Optimisation of extraction}

As reported by Natsume, et al. ${ }^{14} 100 \%$ methanol was selected as extraction solvent to obtain high yield of luteolin and apigenin in plant materials. The total extraction time was also evaluated as reported by Deepak, et $a l^{17}$. However $24 \mathrm{~h}$ maceration of plant materials with methanol $(3 \times 50 \mathrm{ml})$ yielded higher amount of luteolin and apigenin compared to the previously reported methods.

\section{Optimisation of chromatographic conditions}

The HPLC-UV parameters were optimised by investigating the influence of the mobile phase composition and detection wavelength. The initial mobile phase system was tried with gradient elution of methanol and acetate buffer $\mathrm{pH} 4$, but resulted in decrease resolution and tailing of peaks observed. Thus instead of methanol and acetate buffer, gradient elution of acetonitrile and potassium dihydrogen phosphate buffer ( $20 \mathrm{mM}$, adjusted to $\mathrm{pH} 3.5$ with orthophosphoric acid, $\mathrm{v} / \mathrm{v}$ ) was developed. By this method separation, resolution of the peaks was good and tailing of peaks also minimal. Gradient composition was altered to get a fine separation and finally 0 $10 \min 15-60 \% \mathrm{~B}, 10-15 \min 60-75 \% \mathrm{~B}, 15-20 \min 75 \% \mathrm{~B}$, $20-25 \min 75-100 \%$ B set as a mobile phase with the flow rate of $1 \mathrm{ml} / \mathrm{min}$. The UV spectrum of mixer of apigenin and luteolin showed the maximum absorbance at $348 \mathrm{~nm}$ and it was selected as a detection wavelength. The column thermostat was maintained at $30 \pm 1^{\circ} \mathrm{C}$. Before injection column was stabilised with the initial mobile phase concentration of $15 \%$ B for 45 min and after each run column was stabilised with initial gradient concentration for $10 \mathrm{~min}$.

\section{Method validation System suitability}

Six replicate injections of the system suitability solution gave $\%$ RSD values for retention time and peak area within $2 \%$, indicating low variation of the measured values (Table 1). The symmetry of all peaks was $<2$. The resolution (R) between luteolin and apigenin was 3.11, indicating a high degree of peak separation $(\mathrm{R}>2)$. The efficiency of the column, as expressed by the number of theoretical plates, was more than 2000 . These results indicate the suitability of the HPLC system and conditions of the developed method.

\section{Specificity}

Specificity evaluation was carried out by analyzing luteolin and apigenin simultaneously. It was observed that the peaks for each of the drugs were well separated and not interfered with other components. Peak threshold angle $\left(\theta_{\text {th }}\right)$ of all the peaks was found greater than that of peak angle $\left(\theta_{\mathrm{p}}\right)$, values are mentioned in Table 2, indicating the purity of the peaks. Further, peaks obtained by the proposed method corresponding to each of the drugs were seen to be pure. This confirmed that the method used for estimation of the two marker compounds simultaneously was specific.

\section{Calibration curve (Linearity)}

Linear regression analysis confirms that the $r^{2}$ values for both the drugs were $>0.999$ confirming the linear relationship between the concentration of the drugs and area under the curve (Table 3 ). The calibration curves $(n=3)$ constructed for the markers were linear over the concentration range of 1-70 $\mu \mathrm{g} / \mathrm{ml}$ for each marker. 


\section{Precision}

The precision results for the solution at the three concentrations are presented in Table 4 . It was shown that the RSD values for retention time were $<1 \%$, while the RSD values for peak area were $<2 \%$ for both intra- and interday assay precision (intraday, $4 \mathrm{~h}$, six injections; interday, 3 days).

\section{Accuracy}

Recovery of the investigated components ranged from 98.12$99.74 \%$, (Table 5) and their \% RSD values were all $<2 \%$. It was known from recovery tests that the developed methods manifested reliability and accuracy for the measurement of the two components individually.

\section{Limit of detection and Limit of quantification}

The LOD and LOQ for luteolin and apigenin were found to be 0.05 and $0.15 \mu \mathrm{g} / \mathrm{ml}, 0.041$ and $0.13 \mu \mathrm{g} / \mathrm{ml}$, respectively.

\section{Robustness}

Selected parameters like extraction time, different C18 column and $\mathrm{pH}$ remained unaffected by small variations (Table 6). The recovery obtained concluded that the methods are consistent for change in extraction time, column brand and $\mathrm{pH}$.

\section{CONCLUSION}

The developed validated RP-HPLC method enabled the simultaneous determination of luteolin and apigenin in the methanloic leaf extract of Cardiospermum halicacabum. The analytes were identified by their retention times $\left(t_{R}\right)$ and by co-injection with standards. The spiked extract samples with standard compounds ensured that there was no effect of sample matrix on peak response of the analyst of interest. For quantitative determinations, the plant extracts were injected directly on to column and separated under the optimized conditions. The quantity of luteolin and apigenin in Cardiospermum halicacabum was found to be 1.29 and 2.16 $\mathrm{mg} / \mathrm{g}$ respectively. The retention time of luteolin and apigenin was found to be 7.05 and $7.59 \mathrm{~min}$ respectively. Hence the newly developed method enabled the faster analysis of luteolin and apigenin in Cardiospermum halicacabum compared to previously reported method.

\section{REFERENCES}

1. Ragupathy S, Steven G, Newmaster, Gopinadhan P, Candice BN. Exploring Ethnobiological Classifications for Novel Alternative Medicine: A case study of Cardiospermum halicacabum L. (Modakathon, Balloon Vine) as a traditional herb for treating rheumatoid arthritis, Ethnobotany; 2007.p. 19

2. Kumaran A., Karunakaran RJ. Antioxidant activities of the methanol extract of Cardiospermum halicacabum, Pharm. Biol 2006; 44(2): 146151. http://dx.doi.org/10.1080/13880200600596302
3. Gopalakrishnan C, Dhananjayan R, Kameswaran L. Studies on the pharmacological actions of Cardiospermum halicacabum. Indian J Physiol and Pharmacol 1976; 20: 203-206. PMid:1010635

4. VV Asha, Pushpangadan P. Antipyretic activity of Cardiospermum halicacabum. Indian J. Exp Biol 1999; 37: 411-414. PMid:10641181

5. Waako PJ, Gumede B, Smith P, Folb PI. The in vitro and in vivo antimalarial activity of Cardiospermum halicacabum L. and Momordica foetida Schumch. Et Thonn. J Ethnopharmacol 2005; 99: 137-143. http://dx.doi.org/10.1016/j.jep.2005.02.017 PMid:15848033

6. Santakumari G, Pillai NR, Nair RB. Diuretic activity of Cardiospermum halicacabum Linn in rats. J Sci. Res. Plant Med 1981; 2: 32.

7. Rao Venkat N, Chandraprakash K, Kumar Shanta SM. Pharmacological investigation of Cardiospermum halicacabum L. in different animal models of diarrhea. Indian J Pharmacol 2006; 38: 346-349. http://dx.doi .org/10.4103/0253-7613.27703

8. Veeramani C, Pushpavalli G, Pugalendi KV. Anti hyperglycaemic effect of Cardiospermum halicacabum Linn. Leaf extract on STZ-induced diabetic rats. J Appl. Biomed 2008; 6: 19-26.

9. MS Sheeba, VV Asha. Effect of Cardiospermum halicacabum on ethanol-induced gastric ulcers in rats, J. Ethnopharmacol 2006; 106: 105-110. http://dx.doi.org/10.1016/j.jep.2005.12.009 PMid: 16469462

10. Srinivas K, Choudary KA, Rao SS, Satyanarayana T, Rao Krishna RV. Phytochemical examination of Cardiospermum halicacabum Linn. Indian J Nat Prod 1998; 14: 24-27.

11. The European Agency for the Evaluation of Medicinal Products (TEAEMP) Veterinary medicines evaluation unit. EMEA/MRI/664/99FINAL; 1999.

12. Achari B, Chowdhury US, Dutta PK, Pakrashi SC. Two isomeric flavonones from Vitex negundo. Phytochemistry 1984; 23: 703-704. http://dx.doi.org/10.1016/S0031-9422(00)80420-3

13. Darina R, Anna V. UV spectrometric and DC polarographic studies on apigenin and luteolin. Archives of Pharmacal Research 1999; 22(2): 173-178. http://dx.doi.org/10.1007/BF02976542

14. Natsume E, Muto Y, Fukuda K, Tokumaga T, Osakabe N. Determination of rosmarinic acid and luteolin in Perilla frutescens Britton (Labiatae), J. Sci. Food Agric 2006; 86: 891-901. http://dx .doi.org/10.1002/jsfa.2432

15. Bazylko A, Strzelecka H. A HPTLC densitometric determination of luteolin in Thymus vulgaris and its extracts. Fitoterapia 2007; 78(6): 391-5. http://dx.doi.org/10.1016/j.fitote.2007.01.007 PMid:17583444

16. Huang MH, Huang SS, Wang BS, Wu CH, Sheu MJ, Hou WC. Antioxidant and anti-inflammatory properties of Cardiospermum halicacabum and its reference compounds ex-vivo and iv vivo, J. Ethnopharmacol 2010; 133(2): 743-750. http://dx.doi.org/10.1016/ j.jep.2010.11.005 PMid:21073940

17. Deepak M, Sangli GK, Arun PC, Amit A. Quantitative Determination of the Major Saponin Mixture Bacoside A in Bacopa monnieri by HPLC. Phytochem. Anal 2005; 16: 24-29. http://dx.doi.org/10.1002/pca.805 PMid: 15688952

18. Bhandari P, Kumar N, Gupta AP, Singh B, Kaul VK. A rapid RPHPTLC densitometry method for simultaneous determination of major flavonoids in important medicinal plants. J Sep Sci 2007; 30(13): 20926. http://dx.doi.org/10.1002/jssc.200700066 PMid:17654615

19. Li L, Jiang H, Wu H, Zeng S. Simultaneous determination of luteolin and apigenin in dog plasma by RP-HPLC. J Pharm Biomed Anal 2005; 37(3):615-20.http://dx.doi.org/10.1016/j.jpba.2004.11.012 PMid: 15740925

20. ICH. Q2B. Guidance for industry. Validation of Analytical Procedures: Methodology; 1996.

\section{Cite this article as:}

Aiyalu Rajasekaran, Vivekanandan Kalaiselvan, Nagulsamy Sarathikumar, Muthusamy Kalaivani. Simultaneous estimation of Luteolin and Apigenin in methanolic leaf extract of Cardiospermum halicacabum by HPLC. Int. Res. J. Pharm. 2013; 4(7): 109-113 http://dx.doi.org/10.7897/2230-8407.04724 